\title{
The optimal schedule for 5-fluorouracil radiosensitization in colon cancer cell lines
}

\author{
EIKI OJIMA, YASUHIRO INOUE, HIDEKI WATANABE, JUNICHIRO HIRO, \\ YUJI TOIYAMA, CHIKAO MIKI and MASATO KUSUNOKI
}

\begin{abstract}
Department of Gastrointestinal and Pediatric Surgery, Division of Reparative Medicine, Institute of Life Sciences, Mie University Graduate School of Medicine, 2-174 Edobashi, Tsu, Mie 514-8507, Japan
\end{abstract}

Received June 22, 2006; Accepted July 26, 2006

\begin{abstract}
To evaluate the optimal schedule of 5-fluorouracil (5-FU) radiosensitization in rectal cancer, we investigated the interaction between radiation and several doses of 5-FU on colon cancer cell lines based on pharmacokinetics of oral fluoropyrimidine. Cellular cytotoxicity in colon cancer cell lines, LoVo, WiDr and Caco- 2 was determined, using a WST-8 colorimetric assay, after $24 \mathrm{~h}$ exposure to several concentrations of 5-FU and a radiation dose of $5 \mathrm{~Gy}$. Cells were exposed to 5-FU 24 and $0 \mathrm{~h}$ before radiation. 5-FU doses were classified into three groups: uracil-tegafur $(0.01-0.1 \mu \mathrm{M}), \mathrm{S}-1$ (0.1$1.0 \mu \mathrm{M})$ and pharmacokinetic modulating chemotherapy (0.1-10 $\mu \mathrm{M})$. In addition, the effect of 5-FU on the steadystate levels of a human excision repair cross-complementing 1 gene and cell cycle distribution were examined. Regardless of time of 5-FU exposure, all cell growth was significantly inhibited in a dose-dependent manner. In Caco- 2 cells, the cytotoxicity of radiation followed by 5-FU was significantly greater than that of 5-FU followed by radiation, unlike in the other cell lines. The growth inhibitory effect of radiation followed by 5 -FU increased in a dose-dependent manner to reach a plateau at $\mathrm{S}-1$ doses in all cell lines. In cell cycle distribution, 5-FU exposure for $24 \mathrm{~h}$ increased the $\mathrm{S}$ phase fraction in a dose-dependent manner. RT-PCR showed that 5-FU post-treatment graduallly inhibited mRNA expression of ERCC1, which may affect recombination repair efficiency, accounting for the higher tumor sensitivity. Oral fluoropyrimidines, like S-1, that can maintain a constant level of 5FU may be an acceptable alternative radiosensitizer to protracted 5-FU infusion, when the aim of neoadjuvant chemoradiotherapy for rectal cancer is locoregional control.
\end{abstract}

Correspondence to: Dr Masato Kusunoki, Department of Gastrointestinal and Pediatric Surgery, Division of Reparative Medicine, Institute of Life Sciences, Mie University Graduate School of Medicine, 2-174 Edobashi, Tsu, Mie 514-8507, Japan

E-mail: kusunoki@clin.medic.mie-u.ac.jp

Key words: 5-fluorouracil, oral fluoropyrimidine, radiosensitization, rectal cancer

\section{Introduction}

The combination of conventional chemotherapy with radiation is now used in the definitive and adjuvant therapy of the majority of cancer patients. Randomized trials have shown that combination treatment improves survival compared with radiation alone in patients with locally advanced cancers of the head and neck, lung, esophagus, stomach, pancreas and rectum. Despite these resounding clinical successes, the mechanisms by which conventional chemotherapeutic agents produce radiosensitization remain largely unknown.

5-Fluorouracil (5-FU) is one of the most commonly used chemotherapeutic agents for colorectal cancer and it has been used extensively with radiation. There are a number of mechanisms by which 5-FU could increase radiation sensitivity at the cellular level. One mechanism is thought to be through the killing of S phase cells, which are relatively radioresistant (1). This does not account for all of the increased radiation sensitivity produced by the drug because non-cytotoxic concentrations can also increase sensitivity. Radiosensitization under non-cytotoxic conditions occurs only when cells are incubated with the drug before and during radiation. Thus, several studies have suggested that 5-FU should be given continuously during a course of fractionated radiation to achieve radiosensitization of most fractions $(2,3)$.

We have also reported that irradiation and pharmacokinetic-modulating chemotherapy [PMC; combination of $24 \mathrm{~h}$ continuous infusion of 5-FU and oral uracil-tegafur (UFT)] resulted in low local and distant recurrence rates, and high survival rates, even in p53 mutant rectal cancer (4). Moreover, we experimentally proved a potential mechanism for PMC effectiveness in p53 mutant colorectal cancer (5). Infusion of higher 5-FU doses once a week, in combination with lower 5-FU doses using PMC, resulted in two different cytotoxic effects, depending on dose: a) G1-S phase arrest and apoptosis with higher 5-FU concentrations, and b) G2-M phase arrest and mitotic catastrophe with lower 5-FU concentrations. 5-FU in the form of PMC induces dual antitumor effects in both p53 wild-type and mutant colon cancer cell lines.

Indeed, the use of protracted venous infusion of 5-FU has become a standard therapy for rectal cancer (6). However, protracted venous infusion over a 5- to 6-week period is relatively complex, requiring specialized pumps and long-term venous access which makes the patients susceptible to 
Table I. Schematic representation of the chemoradiation schedules.

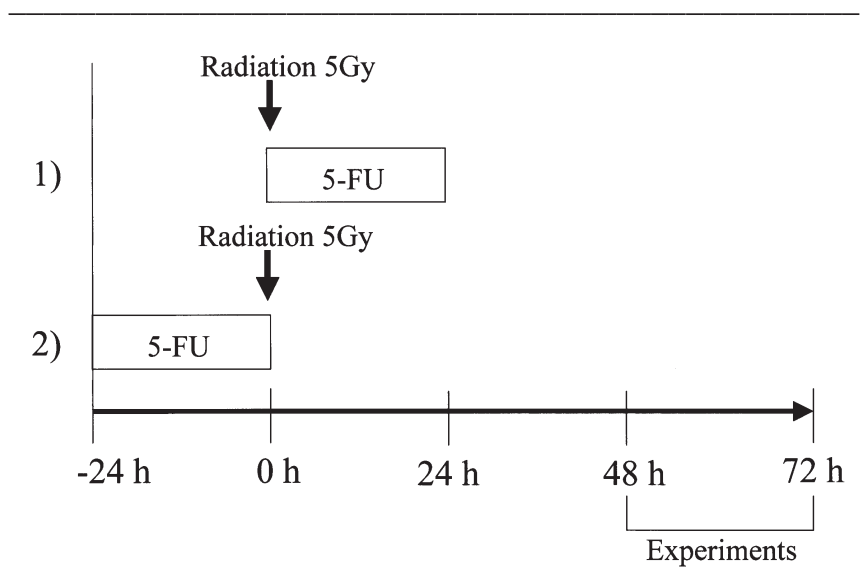

Time (h)

infection or thrombosis. Thus, the introduction of oral forms of 5-FU, such as capecitabine, UFT and S-1, will make protracted, concurrent treatment with drugs and radiation far easier. Although preliminary results using capecitabine and radiation in rectal cancer have been reported $(7,8)$, current practices such as radiation technique and chemotherapy regimen differ between countries, and even between institutions within the same country. So adjuvant treatment for rectal cancer is one of the major controversies in oncology today.

This study aimed to investigate the interaction between radiation and several doses of 5-FU based on the pharmacokinetics of oral fluoropyromidine for colorectal cancer. In addition, we evaluated experimentally the optimal schedule of 5-FU radiosensitization in colorectal cancer.

\section{Materials and methods}

Cell lines and culture conditions. Three colorectal cancer cell lines with different p53 status were used. The cell lines with wild-type p53 were WiDr and Caco-2, and that with mutant p53 was LoVo. WiDr, Caco-2 and LoVo cells were grown in RPMI-1640 medium. All media were supplemented with $10 \%$ fetal bovine serum, $100 \mathrm{U} / \mathrm{ml}$ penicillin and $100 \mu \mathrm{g} / \mathrm{ml}$ streptomycin at $37^{\circ} \mathrm{C}$ and $5 \% \mathrm{CO}_{2}$. Cells were plated at a density of $1.0 \times 10^{4}$ cells $/ \mathrm{cm}^{2}$ plate area and grown for 4 days prior to further experimentation. All experiments were performed with exponentially growing cells.

Anticancer agent. 5-FU was obtained from Sigma Aldrich (St. Louis, MO, USA) and reconstituted in distilled water. The drug was dissolved in appropriate concentrations of distilled water and stored at $-20^{\circ} \mathrm{C}$ until needed.

Irradiation procedure. Colorectal cancer cells were irradiated at room temperature. Cells were treated with 5 Gy of X-ray irradiation by a LiniAc Philips SL75/5x6 MV. Chemoradiation schedules are shown in Table I. The concentration of 5-FU was as described previously (5). 5-FU exposure
Table II. Primer sets for reverse transcripion-PCR.

\begin{tabular}{ll}
\hline ERCC1 & \\
Sense & 5'-GGGAATTTGGCGACGTAATTC-3' \\
Antisense & 5'-GCGGAGGCTGAGGAACAG-3' \\
B-actin & \\
Sense & 5'-ACAGAGCCTCGCCTTTGC-3' \\
Antisense & 5'-GCGGCGATATCATCATCC-3' \\
\hline
\end{tabular}

schedules were as follows: i) no treatment with either 5-FU or irradiation, ii) irradiation alone or iii) 5-FU $(0.01,0.1,1$ and $10 \mu \mathrm{M}$ for $24 \mathrm{~h}$ with irradiation). The time-points of 5-FU exposure were 24 and $0 \mathrm{~h}$ before irradiation.

Growth inhibition assay. Cytotoxicity was evaluated by WST-8 [2-(2-methoxy-4-nitrophenyl)-3-(4-nitrophenyl)-5-(2, 4-disulfophenyl)-2H-tetrazolium, monosodium salt] colorimetric assay. LoVo, WiDr and Caco-2 cells (5000 cells/well) were seeded into 96-well cell plates (Becton-Dickinson Labware, NJ, USA) in $100 \mu \mathrm{l}$ culture medium for $24 \mathrm{~h}$ prior to drug exposure. After $24 \mathrm{~h}$ pre-incubation, cells were treated with various concentrations of 5-FU for the different protocols After drug exposure and/or irradiation, the medium was discarded and replaced with $90 \mu 1$ fresh medium, followed by addition of $10 \mu \mathrm{l}$ WST-8 solution (Cell Counting Kit; Dojindo Laboratories, Japan), and incubated for $4 \mathrm{~h}$ at $37^{\circ} \mathrm{C}$ in an incubator. Cell viability was determined by colorimetric comparison by reading optical density (OD) values from a microplate reader (SoftMax, Molecular Devices, CA, USA) at an absorption wavelength of $450 \mathrm{~nm}$. Cytotoxicity was evaluated by a Cell Counting Kit according to the manufacturer's instructions.

5-FU dosage and pharmacokinetics. Although the $\mathrm{IC}_{50}$ value (the drug concentration responsible for $50 \%$ growth inhibition) of each drug was usually used for the combination study, as much as possible, we used the concentration of each drug as determined from clinical use. 5-FU concentrations were taken from our previous report (5) and from drug information obtained from Kyowa Hakko Kogyo (Tokyo, Japan). Assays of 5-FU plasma concentrations in 23 patients receiving PMC showed serum concentration of 5-FU was $88-1323 \mathrm{ng} / \mathrm{ml}$ ( 0.1-10 $\mu \mathrm{M})$. Drug information on 5-FU from Kyowa Hakko Kogyo shows that plasma concentration of 5-FU reaches $15.3 \mu \mathrm{g} / \mathrm{ml}(100 \mu \mathrm{M})$ after bolus injection at $500 \mathrm{mg} / \mathrm{kg}$ body weight, and also reaches $0.6 \mu \mathrm{g} / \mathrm{ml}(5 \mu \mathrm{M})$ during continuous infusion at $60 \mathrm{mg} / \mathrm{kg}$ every $48 \mathrm{~h}$. In our previous study, UFT alone showed a maximum plasma concentration of 5-FU of $58.7 \mathrm{ng} / \mathrm{ml}(0.1 \mu \mathrm{M})$. UFT itself could not maintain a constant level of 5-FU. 5-FU derived from either UFT or S-1 has a halflife of $40 \mathrm{~min}$ and 2-4 h, respectively (9). The plasma 5-FU concentration was reported to reach a maximum of $1 \mu \mathrm{M}$ after $2 \mathrm{~h}$ of S-1 administration and was maintained at a constant level even after $6 \mathrm{~h}$ (10). Consequently, we classified 5-FU doses into three groups, UFT (0.01-0.1 $\mu \mathrm{M}), \mathrm{S}-1(0.1-1.0 \mu \mathrm{M})$ and PMC (0.1-10 $\mu \mathrm{M})$ based on the pharmacokinetics of oral fluoropyrimidine. 
a

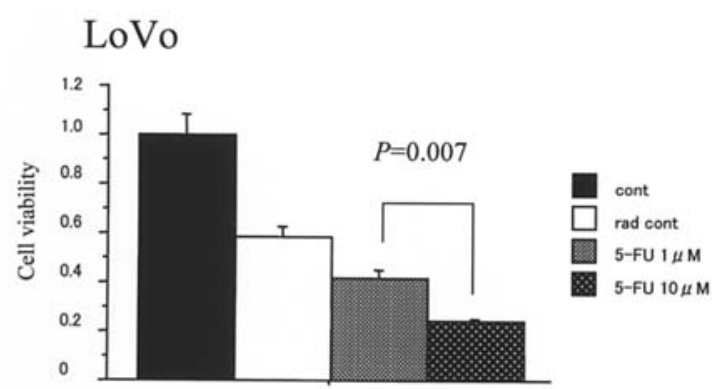

b

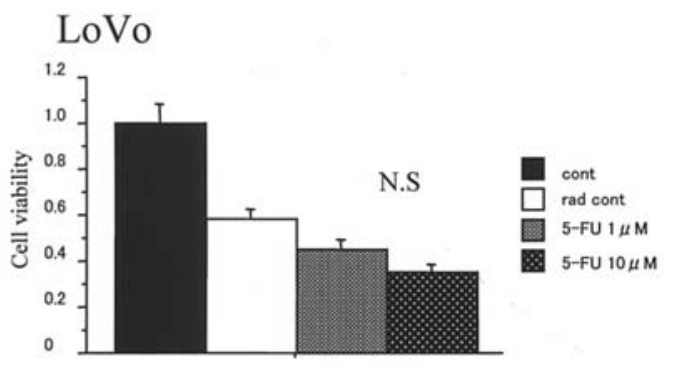

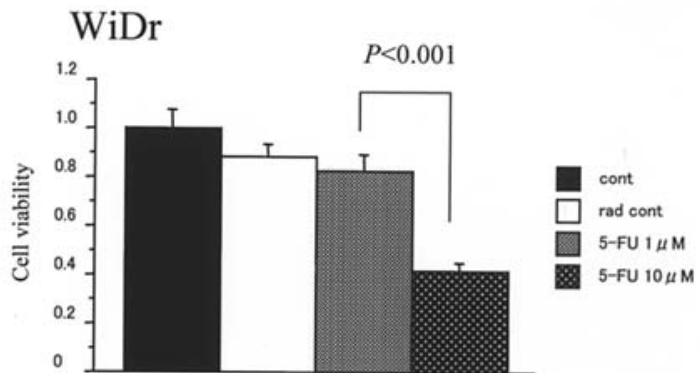

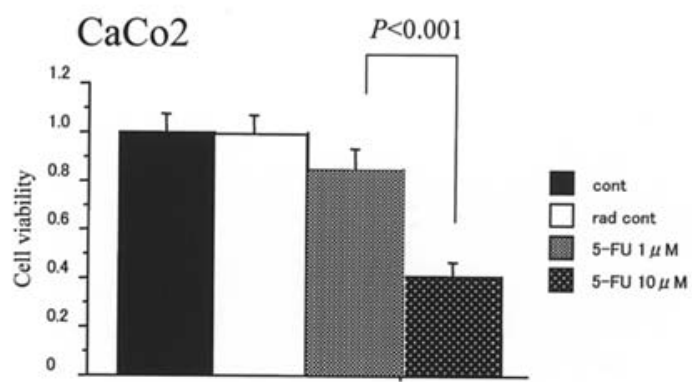

\section{WiDr}

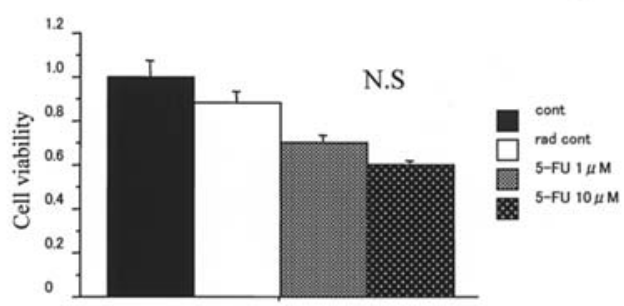

$\mathrm{Caco} 2$

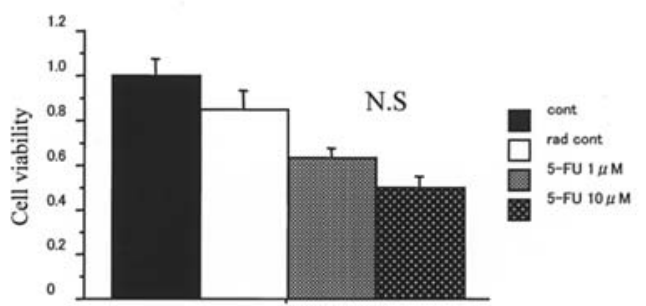

Figure 1. (a), Cells were exposed to 5-FU $24 \mathrm{~h}$ before radiation. Growth of all cell lines was inhibited by cytotoxic doses of 5-FU in a dose-dependent manner. (b), Cells were exposed to 5-FU $0 \mathrm{~h}$ before radiation. Growth of all cell lines was inhibited by cytotoxic doses of 5-FU in a dose-dependent manner.

Drug concentration, exposure time and administration schedule. As mentioned above, we used clinically relevant concentrations of 5-FU. Although we should consider the doubling time of each cell line and subsequently decide exposure time, for experimental simplicity, we used just the 24-h exposure time for the drug. Final concentrations of 5-FU used ranged from 0.01 to $10 \mu \mathrm{M}$. For determining the cytotoxicity of chemoradiation, each cell line in an exponential growth phase was treated for $24 \mathrm{~h}$ with various concentrations of 5-FU. After discarding media containing each drug and replacing it with fresh media, cytotoxicity was evaluated using a WST-8 colorimetric assay. Drug-exposure schedules are shown in Table I. Experiments were done in triplicate for each time-point, and means \pm SD were calculated.

RNA extraction and semi-quantitive RT-PCR analysis. RNA was isolated from each treated cell line using an RNeasy ${ }^{\mathrm{TM}}$ Mini Kit (Qiagen). Oligo(dT)-primed cDNA was prepared from this RNA $(2 \mu \mathrm{g})$ by reverse transcription using an Omniscript RT kit (Qiagen). RT-PCR was performed using specific primers described in Table II. Optimum cycling parameters, in the linear phase of amplification, consisted of $30 \mathrm{sec}$ of denaturation at $94^{\circ} \mathrm{C}, 30 \mathrm{sec}$ of annealing at $60^{\circ} \mathrm{C}$, and $1 \mathrm{~min}$ of elongation at $72^{\circ} \mathrm{C}$, and $23-28$ cycles were performed for 

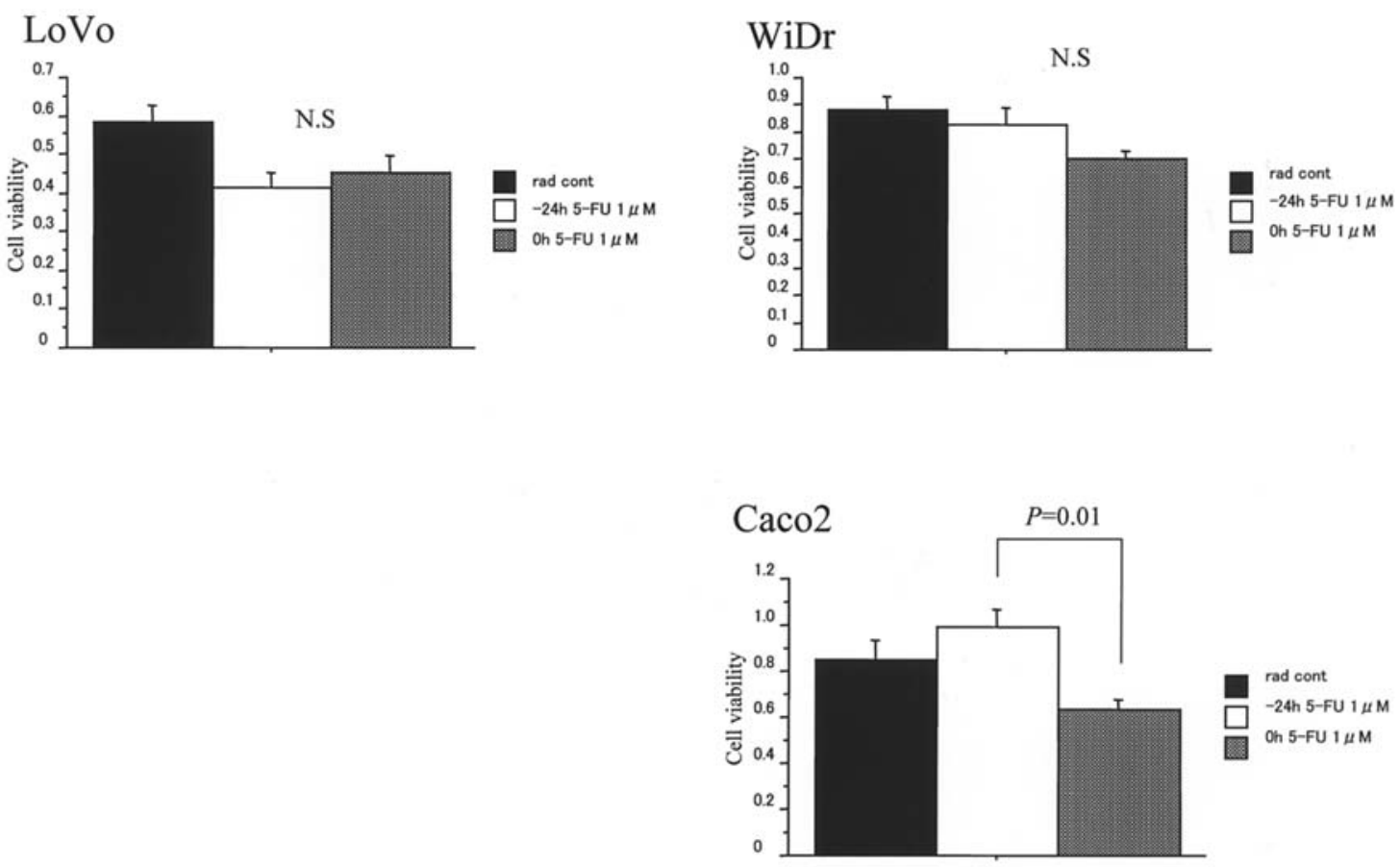

Figure 2. In Caco-2 cells, the cytotoxicity of radiation followed by 5-FU was significantly greater than that of 5-FU followed by radiation, whereas it did not differ significantly in the other cell lines.

the selected gene. A control PCR was also done for B-actin which served as a standard for sample normalization for 25 cycles. Amplified products were separated electrophoretically, visualized and photographed under UV light after ethidium bromide staining.

Flow cytometric analysis. Cell cycle distribution was determined by DNA content analysis after propidium iodide staining. Cells were treated with various concentrations of each drug for $24 \mathrm{~h}$. Cells were then harvested, fixed in $70 \%$ ethanol, incubated with $2 \mathrm{mg} / \mathrm{ml} \mathrm{RNase}$, and stained in $50 \mu \mathrm{g} /$ $\mathrm{ml}$ propidium iodide solution. The DNA content of approximately $1 \times 10^{5}$ stained cells was analyzed using a FACScan flow cytometer. The fraction of the cells in G0-G1, S and G2-M phases was analyzed by DNA program software.

Statistical analysis. Statistical analysis of patient data was performed using Stat View, version 5 software (Abacus Concepts, Berkeley, CA, USA). Results are expressed as means \pm SD Unpaired Student's t-test and Mann-Whitney U test were used for comparison among unpaired groups. $\mathrm{P}<0.05$ was considered statistically significant.

\section{Results}

Growth inhibition by 5-FU and radiation. To elucidate the optimal administration schedule for 5-FU and radiation, we first evaluated the dose-dependent effect of 5-FU on cell viability given at 24 and $0 \mathrm{~h}$ before radiation. Growth of all cell lines was significantly inhibited by cytotoxic doses of 5-FU in a dose-dependent manner at both time-points (Fig. 1).

Differences in cytotoxic effects depending on time of 5-FU treatment. Next, we evaluated the difference in cytotoxic effects depending on the time of exposure to clinically cyto- toxic doses of 5-FU. In Caco-2 cells, in particular, the cytotoxicity of radiation followed by $5-\mathrm{FU}$ was significantly greater than that of 5-FU followed by radiation, whereas it did not differ significantly in the other cell lines (Fig. 2).

Growth inhibition by 5-FU and radiation based on pharmacokinetics of oral fluoropyrimidine. As the cytotoxicity of synchronous treatment was significantly greater than that of 5-FU followed by radiation in Caco-2 cells, we focused on synchronous 5-FU and radiation treatment and examined the cytotoxicity in detail for different 5-FU doses. We also classified 5-FU doses into three groups, UFT (0.01-0.1 $\mu \mathrm{M})$, S-1 $(0.1-1.0 \mu \mathrm{M})$ and PMC $(0.1-10 \mu \mathrm{M})$, according to our previous report. Consequently, the growth inhibitory effect of radiation followed by 5-FU increased in a dose-dependent manner to reach a plateau ( $40 \%$ inhibition) at S-1 doses in all cell lines (Fig. 3).

Cell cycle distribution in Caco-2 cells following 5-FU treatment. To understand the synchronous therapeutic effects, we focused on DNA damage repair and accumulation of cell cycle phase which may be potential mechanisms of radiosensitization in this study. 5-FU exposure for $24 \mathrm{~h}$ increased the $\mathrm{S}$ phase fraction in a dose-dependent manner compared with controls, in agreement with previous findings, which appears to be an important feature of radiosensitization $(11,12)$ (Fig. 4).

Expression of ERCC1 by RT-PCR. We examined the effect of 5-FU on the steady-state levels of mRNA for a human excision repair cross-complementing 1 (ERCC1) gene. RT-PCR showed that 5-FU treatment gradually inhibited mRNA expression for ERCC1, which may affect recombination repair efficiency, accounting for the higher tumor sensitivity observed in cells treated with radiation followed by 5-FU (Fig. 5). 


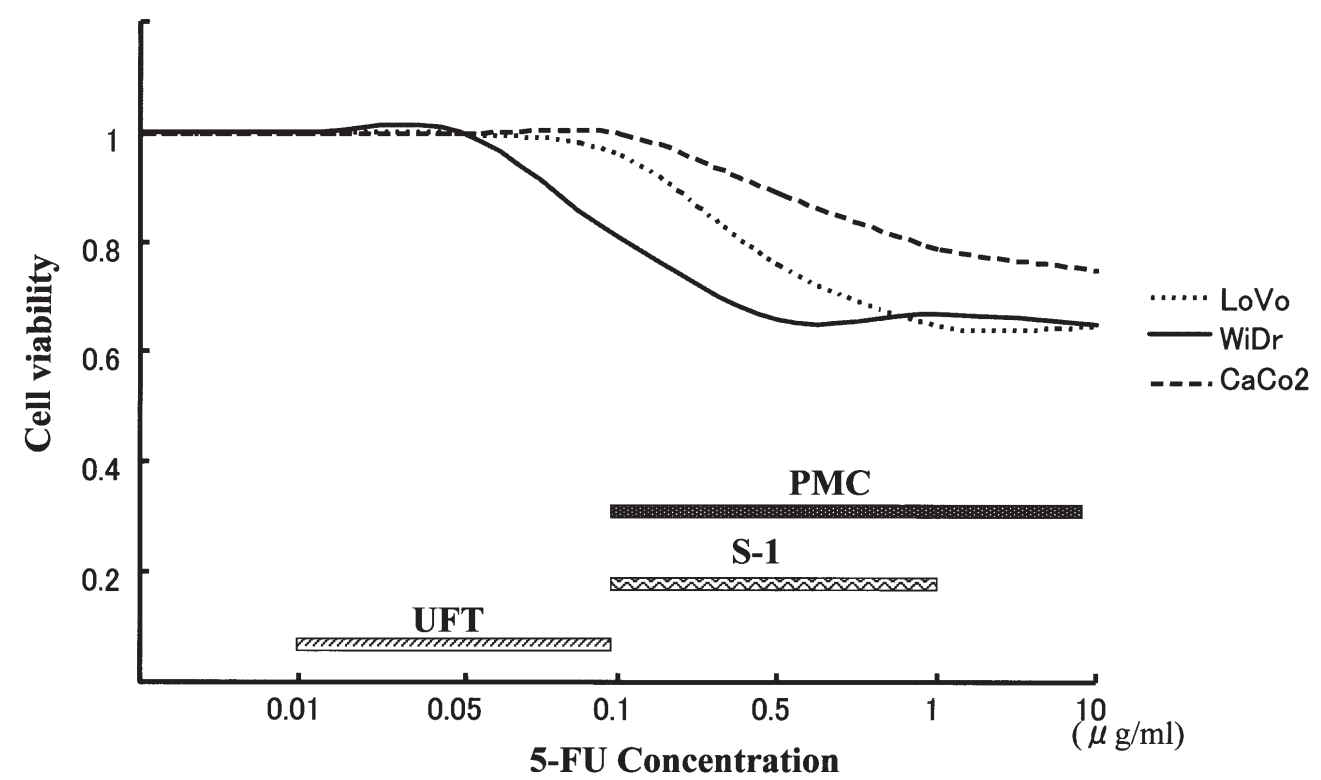

Figure 3. The growth inhibitory effect of radiation followed by 5 -FU increased in a dose-dependent manner to reach a plateau ( 40\% inhibition) at S-1 doses in all cell lines.

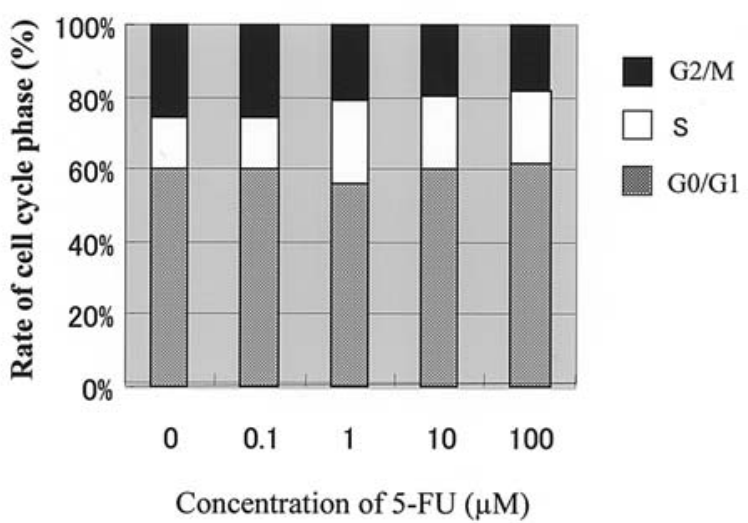

Figure 4. Effect of 5-FU on cell cycle distribution. Cells were treated with 5-FU $(0.1,1$ and $100 \mu \mathrm{M})$ for $24 \mathrm{~h}$. The cells were harvested and the cell cycle distribution was analyzed by flow cytometry. 5-FU exposure increased the $\mathrm{S}$ phase fraction in a dose-dependent manner.

\section{Discussion}

Recently, the interest in preoperative chemoradiotherapy for resectable rectal cancer has gained momentum. This is because it has the advantage of enhancing locoregional control by eliminating microscopic residual disease around the primary tumor and in the draining lymphatics, with a potential impact on overall survival. On the other hand, it may have the disadvantage of treatment-related side effects, especially if radiosensitization is over-enhanced. Although the combination of 5-FU with radiation is now used commonly, it is unclear which of the 5-FU dosing and time schedules provides the best potentiation for radiotherapy. The use of protracted venous infusion of 5-FU has acquired a central role, in combination with radiotherapy, for rectal cancer. However, an important drawback of continuous administration of the drug is the need

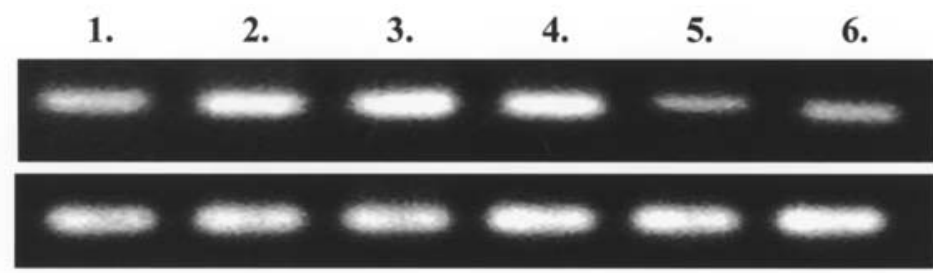

ERCC1

\section{1.control}

\section{2.radiation}

\section{5-FU(0.1uM) + radiation \\ 4.5-FU(1uM) + radiation \\ 5.5-FU(10uM)+radiation \\ 6.5-FU(100u) + radiation}

Figure 5. RT-PCR showed that 5-FU treatment gradually inhibited mRNA expression for ERCC1, which may affect recombination repair efficiency, accounting for the higher tumor sensitivity observed with S-1 doses of 5-FU. 
for implantable access devices and portable infusion pumps, which may lead to complications. Since oral administration of fluoropyrimidines would clearly circumvent this problem, it is expected that the optimal schedule for oral fluoropyrimidine as radiosensitization would be established. Protracted 5-FU infusion also results in inter- and intra-individual variations in plasma concentrations, mainly because of differing levels of dihydropyrimidine dehydrogenase (DPD), the primary catabolic enzyme of 5-FU. In addition, DPD activity displays circadian rhythms. Inhibition or inactivation of DPD has emerged as a potential strategy to reduce the pharmacokinetic variability and improve the efficacy of 5-FU.

Thus, in this study we investigated the interaction between radiation and several doses of 5-FU based on the pharmacokinetics of DPD inhibitory fluoropyromidine. Our goal is to identify areas of potential joint research between clinicians and laboratory scientists that will permit us to apply 5-FU more rationally in combination with radiation for rectal cancer. The combination of tegafur with the DPD inhibitor uracil is known as UFT.

Extensive investigation of UFT in Japan and, more recently, in several other studies, has demonstrated its promising activity in colorectal cancer (13-15). Another DPD inhibitory fluoropyrimidine, $\mathrm{S}-1$, is a novel oral fluoropyrimidine developed in Japan. S-1 consists of tegafur combined with two 5-FU-modulating chemicals, 5-chloro-2,4-dihydroxypyridine (CDHP) and potassium oxonate, at a molar rate of 1:0.4:1. CDHP is a competitive inhibitor of 5-FU catabolism, being 200 times more potent than uracil in inhibiting DPD (10). The idea that S-1 maintains constant high levels of 5-FU is similar to our PMC. S-1 has been shown to exert dramatical antitumor effects on head and neck, as well as gastric cancers (16-18). In addition, clinical trials on combination of S-1 and radiotherapy against advanced oral cancers are about to start in Japan. However, the validity of chemoradiotherapy with S-1 has not yet been clarified. On the other hand, our PMC consists of continuous i.v. infusion of 5-FU over $24 \mathrm{~h}$ for 1 day a week at $600 \mathrm{mg} / \mathrm{m}^{2} /$ day, and an oral dose of UFT, a 5-FU derivative, at $400 \mathrm{mg}$ /day for 5-7 days per week, repeated every week. To better understand and improve chemotherapy, we have investigated PMC experimentally and have obtained important clues regarding the mechanism of oral fluoropyrimidine combined with protracted 5-FU infusion $(5,19,20)$.

In general, combined treatment with 5-FU and radiotherapy leads to dose- and time-dependent enhancement of cell killing $(2,3)$. In the present study, radiosensitization occured when cells were incubated with 5-FU before and during radiation, and growth inhibitory effects were observed in a dose-dependent manner, regardless of the timing of 5-FU treatment. As the cytotoxicity of synchronous treatment was significantly greater than that of 5-FU followed by radiation in the Caco- 2 cell line, we focused on synchronous 5-FU and radiation treatment and examined the detailed cytotoxicity of 5-FU doses. In addition, we classified 5-FU doses into three groups: UFT (0.01-0.1 $\mu \mathrm{M}), \mathrm{S}-1(0.1-1.0 \mu \mathrm{M})$ and PMC (0.1-10 $\mu \mathrm{M})$. Consequently, growth inhibition increased in a dose-dependent manner to reach a plateau at S-1 doses in all cell lines.

To understand these therapeutic effects, we had to search for the factors affecting radiosensitization. Although various intrinsic and extrinsic factors affecting radiosensitization, including hypoxia (21), DNA double-strand breakage repair (22), cell cycle distribution $(11,12)$ and p53 gene status $(23)$, have been reported, we focused on cell cycle distribution and DNA repair which may be a potential mechanism of radiosensitization in this study. Firstly, prolonged exposure to 5-FU increased accumulation of cells in the $S$ phase, in agreement with previous findings, which appears to be an important feature of radiosensitization. Furthermore, we examined the effect of 5-FU on the steady-state levels of mRNA for a human excision repair cross-complementing 1 (ERCC1) gene (24). ERCC1 codes for nucleotide excision repair of radiation- and chemotherapy-induced DNA damage. DNA is the primary cellular target for both chemotherapy- and radiation-induced damage, therefore, DNA repair efficiency could be a limiting factor for therapeutic response, preventing tumor cells from undergoing apoptosis. In this study, 5-FU treatment gradually inhibited mRNA expression for ERCC1 after radiation. These results suggest that $S$ phase progression and decreased ERCC1 expression may affect recombination repair efficiency, accounting for the higher tumor sensitivity observed in irradiation followed by 5-FU. Of course, one can question the relevance of cell studies for the clinical situation, given the obvious differences in tumor growth conditions, blood supply, host reactions and other factors. However, we still feel that these kinds of widely used in vitro models can provide valuable information on comparative cytotoxicity, as we have shown previously $(5,19,20)$.

In conclusion, oral fluoropyrimidine which can maintain a constant level of 5-FU, like S-1, may be an acceptable alternative radiosensitizer to protracted 5-FU infusion, if the aim of neoadjuvant chemoradiotherapy for rectal cancer is locoregional control. Furthermore, optimal chemotherapy should be decided post-operatively for the purpose of systemic control. although prospective clinical trials are needed to determine the actual benefit. This might prevent patients from undergoing expensive, ineffective and potentially harmful therapy, and lead to a more individualized type of multimodal treatment in the near future.

\section{References}

1. Byfield JE: Useful interactions between 5-fluorouracil and radiation in man: 5-fluorouracil as a radiosensitizer. In: Antitumor Drug-radiation Interactions. Hill BT and Bellamy AS (eds). CRC Press, Boca Raton, FL, pp87-105, 1990.

2. Byfield JE, Calabro-Jones P, Klisak I and Kulhanian F: Pharmacologic requirements for obtaining sensitization of human tumor cells in vitro to combined 5-fluorouracil or ftorafur and X-rays. Int J Radiat Oncol Biol Phys 8: 1923-1933 1982.

3. Ishikawa $\mathrm{T}$, Tanaka Y, Ishitsuka $\mathrm{H}$ and Ohkawa T: Comparative antitumor activity of 5-fluorouracil and 5'-deoxy-5-fluorouridine in combination with radiation therapy in mice bearing colon 26 adenocarcinoma. Jpn J Cancer Res 80: 583-591, 1989.

4. Kusunoki M, Yanagi H, Kotera H, Noda M and Yamamura T: Effects of pharmacokinetic modulating chemotherapy using oral UFT and continuous venous 5FU infusion on the prognosis of irradiated rectal carcinomas with p53 overexpression. Int J Oncol 13: 653-657, 1998.

5. Yoshikawa R, Kusunoki M, Yanagi H, et al: Dual antitumor effects of 5-fluorouracil on the cell cycle in colorectal carcinoma cells: a novel target mechanism concept for pharmacokinetic modulating chemotherapy. Cancer Res 1: 1029-1037, 2001

6. Rich TA: Infusional chemoradiation for rectal and anal cancers Oncology 13: 131-134, 1999. 
7. Dunst J, Reese T, Sutter T, et al: Phase I trial evaluating the concurrent combination of radiotherapy and capecitabine in rectal cancer. J Clin Oncol 20: 3983-3991, 2002.

8. Rodel C, Grabenbauer GG, Papadopoulos T, Hohenberger W, Schmoll HJ and Sauer R: Phase I/II trial of capecitabine, oxaliplatin and radiation for rectal cancer. J Clin Oncol 21: 3098-3104, 2003.

9. Peters GJ, van Groeningen CJ, Giaccone G and White RM Jr: Fluorouracil $(5 \mathrm{FU})$ pharmacokinetics in $5 \mathrm{FU}$ prodrug formulations with a dihydropyrimidine dehydrogenase inhibitor. J Clin Oncol 15: 4267-4269, 2001.

10. Van Groeningen CJ, Peters GJ, Schornagel JH, et al: Phase I clinical and pharmacokinetic study of oral S-1 in patients with advanced solid tumors. J Clin Oncol 18: 2772-2779, 2000

11. Davis MA, Tang HY, Maybaum J and Lawrence TS: Dependence of fluorodeoxyuridine-mediated radiosensitization on S phase progression. Int J Radiat Biol 67: 509-517, 1995.

12. Lawrence TS, Davis MA, Tang HY and Maybaum J: Fluorodeoxyuridine-mediated cytotoxicity and radiosensitization require S phase progression. Int J Radiat Biol 70: 273-280, 1996.

13. Ravaud A, Borner M, Schellens JH, et al: UFT and leucovorin in first-line chemotherapy for patients with metastatic gastric cancer. An Early Clinical Studies Group (ECSG)/European Organization for Research Treatment of Cancer (EORTC) phase II trial. Eur J Cancer 37: 1642-1647, 2001.

14. Wang LW, Yang SH, Lin JK, et al: Pre-operative chemoradiotherapy with oral tegafur-uracil and leucovorin for rectal cancer. J Surg Oncol 89: 256-263, 2005.

15. Yang TS, Wang JY, Tang R, Hsu KC and Chen JS: Oral uracil/ ftorafur (UFT) plus leucovorin as first-line chemotherapy and salvage therapy with weekly high-dose 5-fluorouracil/ leucovorin for the treatment of metastatic colorectal cancer. Jpn J Clin Oncol 32: 352-357, 2002.
16. Sakata Y, Ohtsu A, Horikoshi N, Sugimachi K, Mitachi Y and Taguchi T: Late phase II study of novel oral fluoropyrimidine anticancer drug S-1 (1 M tegafur-0.4 M gimestat-1 M otastat potassium) in advanced gastric cancer patients. Eur J Cancer 34: $1715-1720,1998$

17. Baba H, Yamamoto M, Endo K, et al: Clinical efficacy of Scombined with cisplatin for advanced gastric cancer. Gastric Cancer 1: 45-49, 2003.

18. Watanabe A, Taniguchi M, Yamashita T, et al: Phase I/II study of S-1 combined with carboplatin in recurrent and/or metastatic head and neck cancer as outpatient chemotherapy. Head Neck 10: 620-625, 2006.

19. Inoue $\mathrm{Y}$, Tanaka $\mathrm{K}$, Hiro J, et al: In vitro synergistic antitumor activity of a combination of 5-fluorouracil and irinotecan in human colon cancer. Int J Oncol 28: 479-486, 2006.

20. Inoue Y, Shirane M, Miki C, et al: Gene expression profiles of colorectal carcinoma in response to neo-adjuvant chemotherapy. Int J Oncol 25: 1641-1649, 2004

21. Schmidt-Ullrich RK, Dent P, Grant S, Mikkelsen RB and Valerie K: Signal transduction and cellular radiation responses. Radiat Res 153: 245-257, 2000.

22. Tounekti O, Kenani A, Foray N, Orlowski S and Mir LM: The ratio of single- to double-strand DNA breaks and their absolute values determine cell death pathway. Br J Cancer 84: 1272-1279, 2001.

23. Vousden $\mathrm{KH}$ and $\mathrm{Lu} \mathrm{X}$ : Live or let die: the cell's response to p53. Nat Rev Cancer 2: 594-604, 2002

24. Warnecke-Eberz U, Metzger R, Miyazono F, et al: High specificity of quantitative excision repair cross-complementing 1 messenger RNA expression for prediction of minor histopathological response to neoadjuvant radiochemotherapy in esophageal cancer. Clin Cancer Res 10: 3794-3799, 2004. 